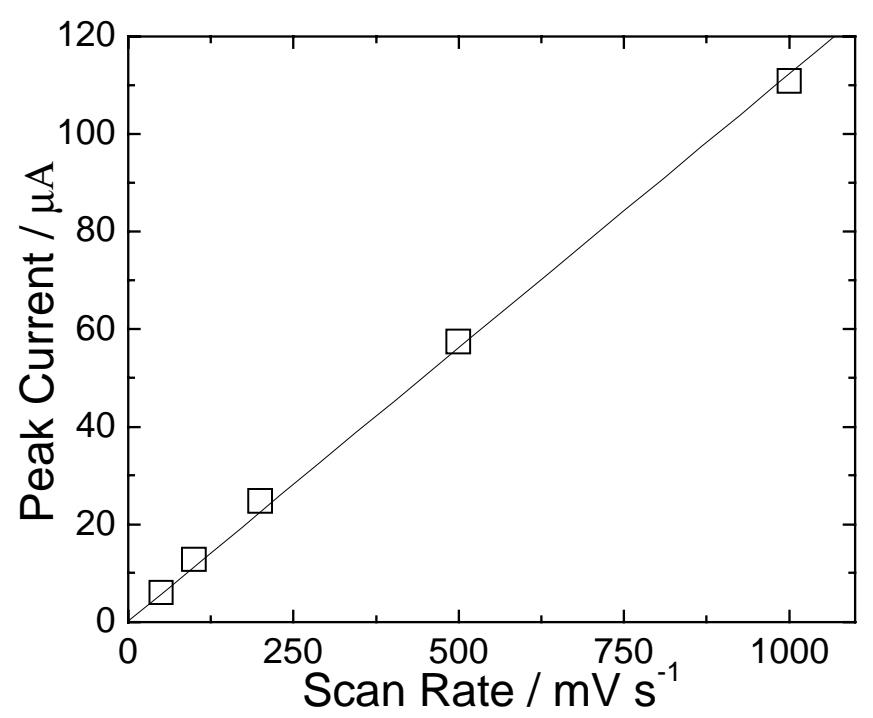

Figure S1. Peak current increases linearly with scan rate for adsorbed $\mathrm{Cu}\left(2,9-\mathrm{Me}_{2^{-}}\right.$ phen). The full width at half max was constant at $120 \mathrm{mV}$. (40 mM acetate buffer, $\mathrm{pH}$ 4.8, $\left.100 \mathrm{mM} \mathrm{NaClO}_{4}\right)$.

\title{
Derivation of Kinetic Models
}

Assume the following mechanism for oxygen reduction:

$$
\begin{aligned}
& {\left[\mathrm{LCu}^{\mathrm{II}}\left(\mathrm{AcO}^{-}\right)_{2}\right]^{0}+\mathrm{e}^{-} \stackrel{\mathrm{k}_{1}}{\underset{\mathrm{k}_{-}}{\longrightarrow}}\left[\mathrm{LCu}^{\mathrm{I}}\left(\mathrm{AcO}^{-}\right)\right]^{0}+\mathrm{AcO}} \\
& {\left[\mathrm{LCu}^{\mathrm{I}}\left(\mathrm{AcO}^{-}\right)\right]^{0}+\mathrm{O}_{2} \stackrel{\mathrm{k}_{2}}{\longrightarrow} \stackrel{\text { fast }}{\longrightarrow}\left[\mathrm{LCu}^{\mathrm{II}}\left(\mathrm{AcO}^{-}\right)-\mathrm{O}_{2}^{-}\right]^{0}}
\end{aligned}
$$

The following abbreviations will be used:

$$
\begin{aligned}
& \mathrm{Cu}^{\mathrm{II}}=\mathrm{LCu}^{\mathrm{II}} \mathrm{A}_{2}^{2-} \\
& \mathrm{Cu}^{\mathrm{I}}=\mathrm{LCu}^{\mathrm{I}} \mathrm{A}^{-}
\end{aligned}
$$

Also, expressions for $k_{1}$ and $k_{-1}$, shown in Equations 5 and 6, are obtained from the Butler-Volmer model:

$$
k_{1}=k_{0} \exp \left(\frac{-\alpha F}{R T}\left(E-E_{c a t}^{0}\right)\right)
$$




$$
k_{-1}=k_{0} \exp \left(\frac{(1-\alpha) F}{R T}\left(E-E_{c a t}^{0}\right)\right)
$$

$F$ is Faraday's constant, $k_{0}$ is the rate constant for electron-transfer, $\alpha=0.5$ is the transfer coefficient, $R$ is the gas constant, and $T=298 \mathrm{~K}$ is the electrode temperature.

The kinetic current, $i_{\mathrm{K}}$, at which the reaction is limited only by the kinetics at the electrode surface and is given by:

$$
i_{K}=n F A \Gamma_{C u^{l}} k_{2}\left[O_{2}\right]
$$

where $\left[\mathrm{O}_{2}\right]$ is the concentration of $\mathrm{O}_{2}$ in air-saturated solutions, and $\Gamma_{\mathrm{A}}$ is the surface coverage of the species A. ${ }^{1}$

The differential rate law for $\Gamma_{\mathrm{Cu}^{I}}$ is given in Equation 10:

$$
\frac{d \Gamma_{C u^{I}}}{d t}=k_{1} \Gamma_{C u^{I I}}-k_{-1} \Gamma_{C u^{I}}-k_{2} \Gamma_{C u^{I}}\left[O_{2}\right]
$$

Assuming steady-state kinetics for Equation 1, Equation 10 yields:

$$
0=k_{1} \Gamma_{C u^{I I}}-k_{-1} \Gamma_{C u^{I}}-k_{2} \Gamma_{C u^{I}}\left[O_{2}\right]
$$

and so,

$$
\Gamma_{C u^{I}}=\frac{k_{1} \Gamma_{C u^{I I}}}{\left(k_{-1}+k_{2}\left[O_{2}\right]\right)} .
$$

Since the total coverage of copper species $\Gamma_{t o t}=\Gamma_{C u^{I I}}+\Gamma_{C u^{I}}$, then:

$$
\Gamma_{C u^{I}}=\frac{k_{1}\left(\Gamma_{t o t}-\Gamma_{C u^{I}}\right)}{\left(k_{-1}+k_{2}\left[O_{2}\right]\right)} .
$$

Rearrangement of Equation 13 yields:

$$
\Gamma_{C u^{I}}=\frac{k_{1} \Gamma_{t o t}}{k_{1}+k_{-1}+k_{2}\left[O_{2}\right]}
$$

Now, substitution of equation 14 into Equation 9 yields:

$$
i_{K}=\frac{n F A k_{1} k_{2} \Gamma_{t o t}\left[O_{2}\right]}{k_{1}+k_{-1}+k_{2}\left[O_{2}\right]}
$$


Inverting Equation 15 yields:

$$
\frac{1}{i_{K}}=\frac{1}{n F A k_{2} \Gamma_{t o t}\left[O_{2}\right]}+\frac{k_{-1}}{n F A k_{2} k_{1} \Gamma_{t o t}\left[O_{2}\right]}+\frac{1}{n F A k_{1} \Gamma_{t o t}}
$$

Substituting Equations 5 and 6 for $k_{1}$ and $k_{-1}$ and taking $\alpha=0.5$ yields:

$$
\frac{1}{i_{K}}=\frac{1}{n F A k_{2} \Gamma_{t o t}\left[O_{2}\right]}+\frac{\exp \left(\frac{F}{R T}\left(E-E_{c a t}^{0}\right)\right)}{n F A k_{2} \Gamma_{\text {tot }}\left[O_{2}\right]}+\frac{\exp \left(\frac{0.5 F}{R T}\left(E-E_{c a t}^{0}\right)\right)}{n F A k_{0} \Gamma_{t o t}}
$$

Assume that the rate of the reaction depends only upon $\mathrm{O}_{2}$-binding and that the electron-transfer kinetics of Equation 1 are fast. That is, the rate constant, $k_{0}$, of electron transfer for the reduction of $\mathrm{Cu}^{\mathrm{II}}$ to $\mathrm{Cu}^{\mathrm{I}}$ approaches $\infty$. Then Equation 15 reduces to:

$$
\frac{1}{i_{K}}=\frac{1+\exp \left(\frac{F}{R T}\left(E-E_{\text {cat }}^{0}\right)\right)}{n F A k_{2} \Gamma_{\text {tot }}\left[O_{2}\right]}
$$

and so,

$$
i_{K}=\frac{n F A k_{2} \Gamma_{t o t}\left[O_{2}\right]}{1+\exp \left(\frac{F}{R T}\left(E-E_{c a t}^{0}\right)\right)}
$$

This analysis is used in Figure 9 in the paper.

Alternatively, if we assume $k_{0}$ to be finite then we can estimate it from the peak-to-peak separation of CVs: $k_{0}=5.9 \mathrm{~s}^{-1}$ for $\mathrm{Cu}\left(3,8-\mathrm{CO}_{2} \mathrm{Et}-4,7-\mathrm{Cl}_{2}\right.$-phen $)(249 \mathrm{mV}$ peak-to-peak splitting at scan rate $=3200$ $\mathrm{mV} / \mathrm{s})$ and $k_{0}=10.9 \mathrm{~s}^{-1}$ for $\mathrm{Cu}\left(2,9-\mathrm{Me}_{2}\right.$-phen $)(185 \mathrm{mV}$ peak-to-peak splitting at scan rate $=3200$ $\mathrm{mV} / \mathrm{s}){ }^{2}$ Equation 15 was used to model the potential-dependence of $i_{\mathrm{K}}$ for $\mathrm{Cu}\left(3,8-\mathrm{CO}_{2} \mathrm{Et}-4,7-\mathrm{Cl}_{2}-\mathrm{phen}^{2}\right.$ and $\mathrm{Cu}\left(2,9-\mathrm{Me}_{2}-\right.$ phen) (Figure S2). The solid lines represent the calculated kinetics current according to Equation 17, and the dotted lines according to Equation 15. 

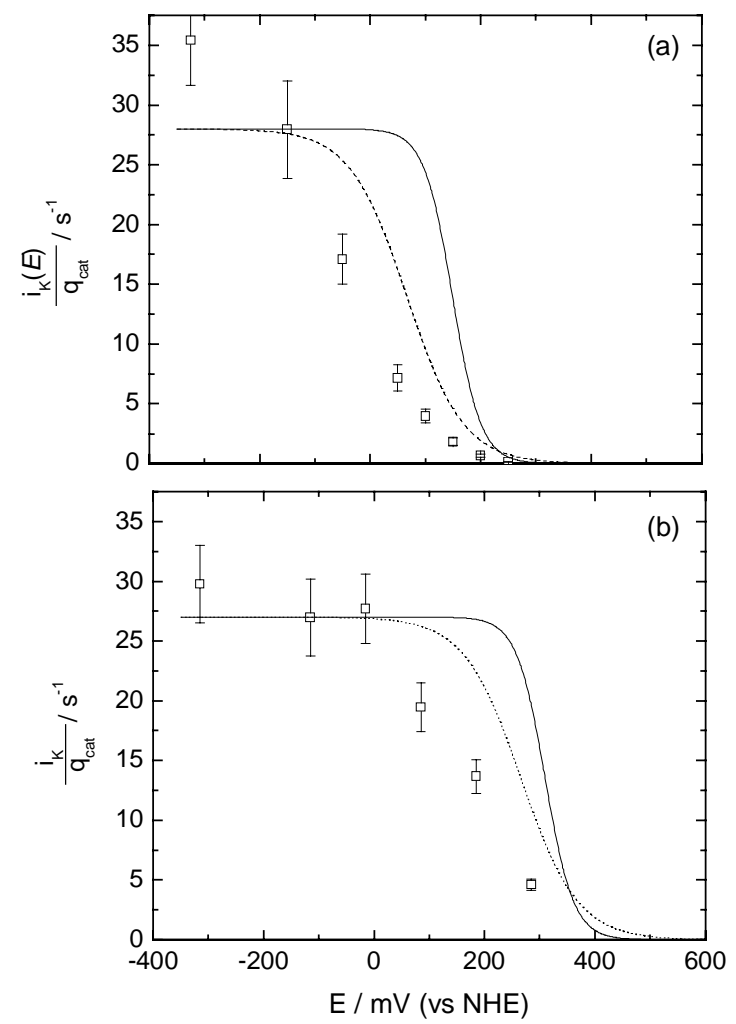

Figure S2. Kinetic currents as a function of potential for (a) $\mathrm{Cu}\left(3,8-\mathrm{CO}_{2} \mathrm{Et}-4,7-\mathrm{Cl}_{2}\right.$-phen) and (b) $\mathrm{Cu}\left(2,9-\mathrm{Me}_{2}\right.$-phen). The solid lines are theoretical Nernstian responses for each catalyst with $E_{\text {cat }}^{0}=E_{1 / 2}$. The dashed lines are theoretical responses when the kinetics of the reduction of $\mathrm{Cu}^{\mathrm{II}}$ is taken into account. (Data in (a) was taken in a $20 \mathrm{mM} \mathrm{AcO}^{-}$and 20 $\mathrm{mM}$ HOAc buffer at $\mathrm{pH} 4.8,100 \mathrm{mM}$ $\mathrm{NaClO}_{4}$. Data in (b) was taken in $20 \mathrm{mM}$ $\mathrm{AcO}^{-}$and $72 \mathrm{mM} \mathrm{HOAc} \mathrm{buffer} \mathrm{at} \mathrm{pH} 4.2$, $100 \mathrm{mM} \mathrm{NaClO}_{4}$

\section{Other Ligands Investigated}

\begin{tabular}{|c|c|c|}
\hline & $\begin{array}{c}E_{\text {cat }}^{0} \\
\mathrm{mV} \text { vs. } \\
\mathrm{NHE}\end{array}$ & $\begin{array}{c}E_{\mathrm{O}_{2}} \\
\mathrm{mV} \text { vs. } \\
\mathrm{NHE}\end{array}$ \\
\hline
\end{tabular}

Table S1. Four extra ligands are reported here. $E_{\text {cat }}^{0}$ of the $\mathrm{Cu}$ complex of each ligand is reported in the first column, and the $\mathrm{O}_{2}$-reduction peak of the air-saturated C.V., $E_{\mathrm{O}_{2}}$, is reported in the second column. $\mathrm{O}_{2^{-}}$ reduction kinetics were not investigated for these ligands. All data taken in aqueous solutions of $100 \mathrm{mM} \mathrm{NaClO}$, $20 \mathrm{mM} \mathrm{NaAcO}, 20 \mathrm{mM} \mathrm{AcOH}$, $\mathrm{pH} 4.8$.

Four ligands not discussed in the main text are shown in Table S1. 5,6-epoxy-phen was obtained from a commercial source. 2- $\mathrm{CO}_{2} \mathrm{H}$-phen, ${ }^{3}$ 3-Br-phen, ${ }^{4,5}$ and 3,8- $\mathrm{Br}_{2}$-phen, ${ }^{6}$ were prepared according to literature procedures. 3-Br-phen and 3,8- $\mathrm{Br}_{2}$-phen were purified by chromatography over silica with 
dichloromethane saturated with wet ammonia as the eluent. This eluent yields well-separated TLC spots with no tailing effects and has proven extremely useful in the purification of these phen derivatives.

(1) Bard, A. J.; Faulkner, L. R. Electrochemical Methods: Fundamentals and Applications; 2nd ed.; John Wiley \& Sons, Inc., 2001, pp 335-344.

(2) Laviron, E. J. Electroanal. Chem. 1979, 101, 19-28.

(3) Corey, E. J.; Borror, A. L.; Foglia, T. Tetrahedron Lett. 1965, 30, 288-290.

(4) Connors, P. J.; Tzalis, D.; Dunnick, A. L.; Tor, Y. Z. Inorg. Chem. 1998, 37, 1121-1123.

(5) Tzalis, D.; Tor, Y.; Failla, S.; Siegel, J. S. Tetrahedron Lett. 1995, 36, 3489-3490.

(6) Saitoh, Y.; Koizumi, T.; Osakada, K.; Yamamoto, T. Can. J. Chem. 1997, 75, 1336-1339. 